\title{
Family history of breast cancer as a second primary malignancy in relatives: a nationwide cohort study
}

\author{
Guoqiao Zheng $^{1^{*}}$ (D), Jan Sundquist ${ }^{1,2,3}$, Kristina Sundquist $^{1,2,3}$ and Jianguang Ji ${ }^{1}$
}

\begin{abstract}
Background: With the increasing number of breast cancer (BC) diagnosed as a second primary malignancy after a first primary non-breast cancer (BCa-2), it is unclear about the familial risk of $B C$ among women with a first-degree relative (FDR, parents or siblings) affected by a $B C a-2$.

Methods: In this Swedish nationwide cohort study, 5315 women with a FDR affected by BCa-2 and 115,048 women with a FDR affected by $B C$ as the first primary cancer (BCa-1) were followed for the first primary invasive BC diagnosis. Relative risk (RR) of $\mathrm{BC}$ was estimated through Poisson regression by using 2,743,777 women without a family history of cancer as reference. The risk was stratified by the diagnostic age of BC in FDR, proband type, the time interval between the first primary cancer and BCa-2 in FDR as well as the site of first primary cancer diagnosed in FDR before BCa- 2 . We also calculated the cumulative incidence of $B C$ from birth to a specific age for the three groups.

Results: The cumulative incidence from birth to age 70 was $10 \%$ among women with a family history of BCa-2. The RR of $\mathrm{BC}$ with a family history of $\mathrm{BCa}-2(\mathrm{RR}, 1.68,95 \% \mathrm{Cl}, 1.49$ to 1.88$)$ was comparable to that with $\mathrm{BCa}-1$ (1.68, 1.63 to 1.73$)$. The risk was largely consistent irrespective of proband type. The age of onset of BCa-2 in FDR (RR early-onset, 1.72 vs. RR late-onset 1.67) had less influence on the risk compared to BCa-1 in FDR (1.89 vs. 1.63). In the analysis stratified by the time between the first primary cancer and $\mathrm{BCa}-2$ in relatives, the risks were largely similar. For the site of first primary cancer diagnosed in FDR before $\mathrm{BCa}-2$, the increased $\mathrm{BC}$ risk was found in women whose FDRs were diagnosed with first primary gastric, colorectal, endometrial, ovarian, nervous system and endocrine gland cancers, and non-Hodgkin lymphoma.
\end{abstract}

Conclusions: Women with a family history of $\mathrm{BCa}-2$ have a similar overall $\mathrm{BC}$ risk as those with a family history of $\mathrm{BCa}-$ 1. The risk varied according to the site of first primary cancer diagnosed in FDR before BCa-2.

Keywords: Breast carcinoma, Cancer incidence, Familial clustering, Multiple primary cancer

\section{Introduction}

Breast cancer $(\mathrm{BC})$ is the leading cause of cancer death among women worldwide [1]. Family history of $\mathrm{BC}$ in first-degree relative (FDR) is one of the important risk factors. The relative risk (RR) of $\mathrm{BC}$ in women was estimated

\footnotetext{
* Correspondence: guogiao.zheng@med.lu.se

${ }^{1}$ Center for Primary Health Care Research, Lund University/Region Skåne, Jan Waldenströms gata 35, 20502 Malmö, Sweden

Full list of author information is available at the end of the article
}

at about 1.8 with one FDR affected by BC [2-4]. Many medical organizations recommend screening with mammography for women aged 40 or above with an average risk of $\mathrm{BC}$. Most screening guidelines acknowledge the need for earlier screening for those at a higher risk [5], and the risk-adapted starting age has been proposed in patients with a family history of $\mathrm{BC}[6]$. Unfortunately, no previous studies have considered the order of the primary BC. Multiple primary BC in a relative is a well-established

(c) The Author(s). 2021 Open Access This article is licensed under a Creative Commons Attribution 4.0 International License, which permits use, sharing, adaptation, distribution and reproduction in any medium or format, as long as you give appropriate credit to the original author(s) and the source, provide a link to the Creative Commons licence, and indicate if changes were made. The images or other third party material in this article are included in the article's Creative Commons licence, unless indicated otherwise in a credit line to the material. If material is not included in the article's Creative Commons licence and your intended use is not permitted by statutory regulation or exceeds the permitted use, you will need to obtain permission directly from the copyright holder. To view a copy of this licence, visit http://creativecommons.org/licenses/by/4.0/ The Creative Commons Public Domain Dedication waiver (http://creativecommons.org/publicdomain/zero/1.0/) applies to the data made available in this article, unless otherwise stated in a credit line to the data. 
risk factor. While there is limited evidence on the familial risk associated with the diagnosis of $\mathrm{BC}$ as a second primary malignancy after a cancer other than $\mathrm{BC}(\mathrm{BCa}-2)$. The etiology of $\mathrm{BCa}-2$ is not totally the same as $\mathrm{BC}$ diagnosed as a first primary malignancy (BCa-1). Some of the risk factors that lead to a diagnosis of $\mathrm{BCa}-2$, such as treatment from the first primary cancer, are absent for BCa-1 and are not shared among family members. Despite that $\mathrm{BC}$ is the most common second primary cancer among women [7], it is unknown whether the familial risk remains unchanged when the FDRs are diagnosed with a BCa-2.

The aim of the study was to estimate the familial risk of $\mathrm{BC}$ among women whose FDR was diagnosed with BCa-2 after a first primary non-breast cancer. The findings may bridge the knowledge gap of the family history of $\mathrm{BCa}-2$, given the increasing number of cancer patients diagnosed with $\mathrm{BCa}-2$. It will also be important for the realization of personalized cancer prevention and early detection.

\section{Methods}

\section{Data resources}

This study was conducted with linkage of several Swedish national registers using each person's unique identification number. To preserve confidentiality, this ID number was replaced by a serial number. The Swedish Cancer Registry recorded all incident tumors from 1958 with more than $90 \%$ coverage $[8,9]$. The regional registries follow the same rules of registration and carry out coding, checking, and correction of the records. The notification of cancer was based on the 7th version of the International Classification of Disease (ICD-7). The diagnosis of second primary cancer is reliable in the Swedish Cancer Registry as all cancer cases included in this register were reported by both the clinician and the pathology laboratory after verification of morphological examinations. An ad hoc study showed 98\% diagnostic accuracy of second neoplasms in the registry and none were found to be a metastastic cancer [10]. The Swedish Multi-Generation register recorded all the offspring born after 1931 with their biological parents. The linkage of the two registers enabled the identification of any cancer (first primary, second primary, et al) in relatives. The individuals were further linked to Total Population Register to retrieve information on socioeconomic status and place of residence.

\section{Family history}

The design of the familial risk analysis is shown in Fig. 1 with an example. Family history of $\mathrm{BCa}-2$ was defined as $\mathrm{BC}$ diagnosis after first primary cancer other than $\mathrm{BC}$ in FDR (parents or siblings); as shown in the example of Fig. 1a, the mother was diagnosed with $\mathrm{BC}$ at age 2 after other cancer. Family history of $\mathrm{BCa}-1$ was defined as single $\mathrm{BC}$ diagnosis as first primary cancer in FDR (Fig. 1b). Women without cancer diagnosis in FDR were used as reference group (Fig. 1c). The family history in the study period was independent of the time of diagnosis of $\mathrm{BCa}$ 1 or $\mathrm{BCa}-2$ in FDRs i.e., even if the FDR was diagnosed with $\mathrm{BCa}-1$ or $\mathrm{BCa}-2$ after the death of an individual, this individual was considered to have a family history of $\mathrm{BCa}-1$ or $\mathrm{BCa}-2$, respectively.

\section{Study population and follow-up}

The selection of the population is shown in Supplementary Fig. 1. Initially, 4,048,571 women in the offspring generation with a maximum age of 83 years were included from the Swedish population register. We removed 21,793 women with any FDR affected by multiple primary $\mathrm{BC}$ ( $\mathrm{BC}$ as both first and second primary cancers), as family history of which has been used as an indicator of increased $\mathrm{BC}$ risk for many years [11]. It has been shown that increased $\mathrm{BC}$ risk was associated with

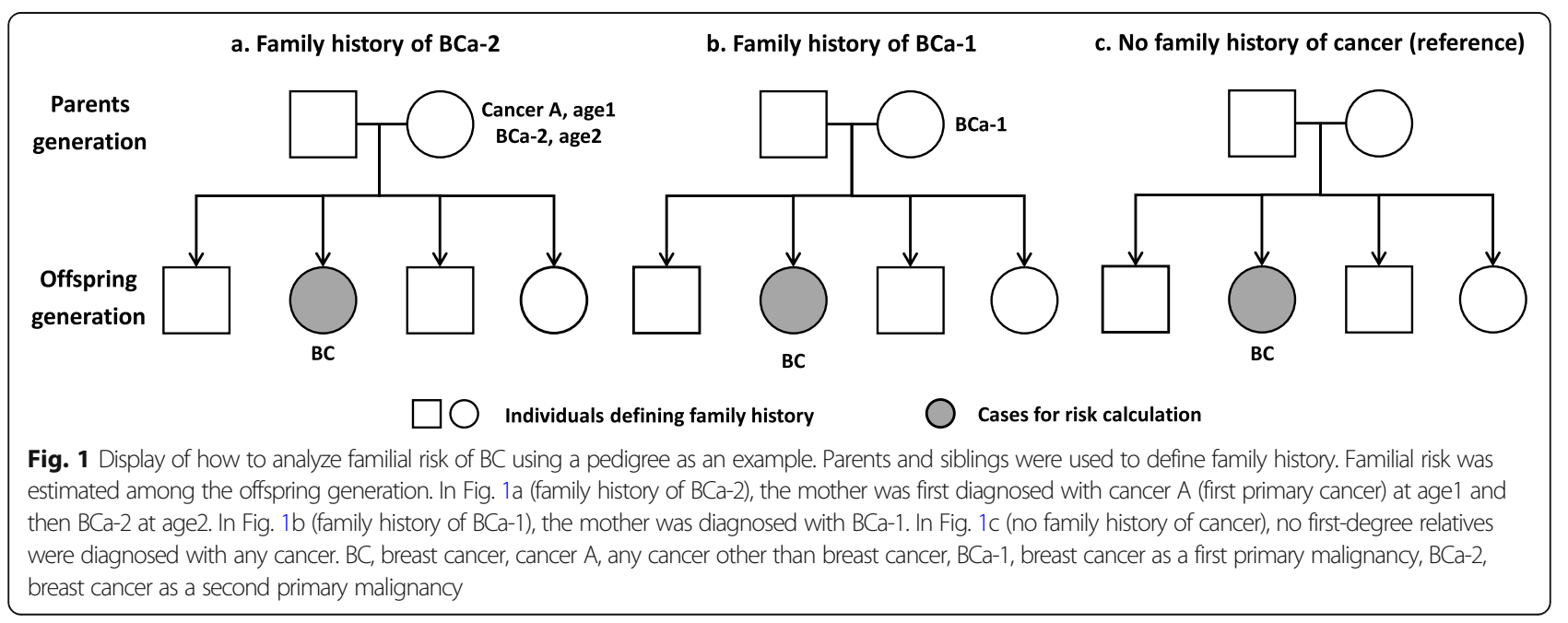


the diagnosis of cancer other than $\mathrm{BC}$ in relatives and the number of the affected relatives had a dosedependent effect on the risk [12]. Therefore, we further removed 1,147,108 women with any FDR affected by any other first primary cancer except those with FDR affected by BCa-2. A small number of women with an FDR affected by BCa-1 and another FDR affected by BCa-2 were removed $(N=395)$. We additionally removed women who had more than one FDR affected by $\mathrm{BCa}-1$ or $\mathrm{BCa}-2$, or women who had FDR affected by higher order primary cancers (such as the third or fourth primary $\mathrm{BC}$ ) to keep the analyses comparable among different categories. We excluded the latter group, as it is difficult to distinguish which primary cancer contributed to risk modification. Ultimately, a total of 5315 women with a family history of $\mathrm{BCa}-2$ were retained for the main analysis together with 2,743,777 women who had relatives without any cancer, and 115,048 women with a family history of BCa-1. We also analyzed the risk keeping families with multiple affected FDRs or FDRs with higher order primary cancers as a supplementary result (Supplementary Fig. 1). All the women were followed for a first primary invasive BC diagnosis from 1958, the year of birth, or immigration, whichever came the latest. The follow-up was ended in 2015, the year of cancer diagnosis, death or migration which came the earliest.

\section{Statistical analysis}

The incidence rate ratio estimated from Poisson regression was used to describe relative risk (RR) by using women without FDR affected by cancer as reference group. In the model, age groups ( 5 years), periods ( 5 years), parity (number of live birth: $0,1,2,3$, over 3), socioeconomic status (blue-collar worker, white-collar worker, farmer, private business, professional, or other/unspecified) and place of residence (big cities, northern Sweden, southern Sweden and unspecific) were also adjusted for. Number of childbirth was considered as null parity is a risk factor for breast cancer [13]. The twosided $95 \%$ confidence interval $(\mathrm{CI})$ of the relative risk was calculated. The risk was further stratified based on the proband type (family history from mother, sister, and father and brother), age at the $\mathrm{BC}$ diagnosis in $\mathrm{FDR}(\leq 50$ and $>50$ years old), years between first primary cancer and $\mathrm{BCa}-2$ diagnosis in FDR (groups based on quartiles), and sites of first primary cancer before BCa-2 in FDR. Additionally, smoking-related cancers including oral, esophageal, stomach, pancreas, lung, cervix, kidney, and bladder cancers [14], and hematological cancers including non-Hodgkin's lymphoma, Hodgkin's lymphoma, myeloma, and leukemia were also considered respectively as first primary cancer before $\mathrm{BCa}-2$. The cumulative incidence from birth to a specific age was estimated with consideration of competing risk of being diagnosed with other cancer and death. All the statistical analyses were completed in SAS 9.4.

\section{Results}

The median (interquartile range, IQR) age at diagnosis of the BCa-1 and BCa-2 in relatives were 58 (49-67) years and 68 (59-76) years, respectively. For women with family history of $\mathrm{BCa}-2$, the median time between the first primary cancer and $\mathrm{BCa}-2$ diagnoses in FDR was 8 (3-18) years. At the end of the follow-up, 5345 women, who had a FDR affected by BCa-1, were diagnosed with $\mathrm{BC}$ at the median age of 54 (47-62) years, and 298 women, who had a FDR affected by $\mathrm{BCa}-2$, were diagnosed with $\mathrm{BC}$ at the median age of 54 (48-62) years.

Table 1 shows that the overall RR of $\mathrm{BC}$ was similar for women with family history of either BCa-1 (RR, 1.68, $95 \% \mathrm{CI}, 1.63$ to 1.73$)$ or $\mathrm{BCa}-2(1.68,1.49$ to1.88). When stratifying the analysis based on the age at diagnosis of $\mathrm{BC}$, risk was relatively higher for women whose FDR was affected at younger age ( $\leq 50$ years). The effect of age at onset was stronger for BCa-1 (difference in RR, 1.89$1.63=0.26)$ in comparison to $\mathrm{BCa}-2(1.72-1.67=0.05)$. When $\mathrm{BCa}-2$ was diagnosed in mother or sister, the risk was still equivalent to that with family history of $\mathrm{BCa}-1$, but it was high for women with male FDR affected by BCa-2 (2.19, 0.98 to 4.87$)$. However, only six BC patients had a family history of male $\mathrm{BCa}-2$. The cumulative incidence of $\mathrm{BC}$ from birth to a specific age is displayed in Fig. 2. By age 70, the cumulative incidence was 10.7 (95\%CI, 10.3 to 11.1$) \%$ and $11.4(9.8-13.3) \%$ for women whose mother had $\mathrm{BCa}-1$ and $\mathrm{BCa}-2$, respectively. For those with an affected sister, the corresponding incidences were 10.7 (10.1 to 11.2 ) \% and 10.6 (8.3 to 13.6) \%, and for those with an affected father or brother, the number was 12.2 (8.4 to 17.8 ) \% and 19.1 (8.5 to 43.2) \%. The incidence curves had overlaps between family history of $\mathrm{BCa}-1$ and $\mathrm{BCa}-2$ for the three type of family relationship.

Women with a family history of BCa-2 were classified into four groups based on quartiles of the interval $(3,8$ and 18 years) between the first primary cancer and $\mathrm{BCa}-2$ diagnosed in relatives (Fig. 3). When relatives were diagnosed with $\mathrm{BCa}-2$ soon after the first primary cancer (within 3 years), the risk of $\mathrm{BC}$ was 1.91 (1.52 to 2.39), and it remained stable for $\mathrm{BCa}-2$ that occurred after 3 years.

$\mathrm{BC}$ risk with a family history of $\mathrm{BCa}-2$ was further estimated according to the sites of the first primary cancer diagnosed before BCa-2 in FDR (Table 2). The risk varied for different first primary cancers, among which, cancers of stomach, colorectal, endometrium, ovary, nervous system and endocrine gland, and non-Hodgkin lymphoma as well as smoking-related and hematological cancers had a significantly increased RR. Specifically, for the tumor in the nervous system, two-thirds of the relatives were diagnosed with meningioma. Among the 20 relatives with endocrine gland tumors, 18 had parathyroid cancers. 
Table 1 Breast cancer risk in women when one FDR was diagnosed with BCa-1 or BCa-2

\begin{tabular}{|c|c|c|c|c|c|c|}
\hline \multirow[t]{2}{*}{ Category } & \multicolumn{3}{|c|}{ One FDR affected by BCa-1 } & \multicolumn{3}{|c|}{ One FDR affected by BCa-2 } \\
\hline & $\mathrm{N}^{\mathrm{a}}$ & $\mathbf{R R}^{\mathbf{b}}$ & $95 \% \mathrm{Cl}$ & $\mathrm{N}^{\mathrm{a}}$ & $\mathbf{R R}^{\mathbf{b}}$ & $95 \% \mathrm{Cl}$ \\
\hline Overall & 5345 & 1.68 & $1.63-1.73$ & 298 & 1.68 & $1.49-1.88$ \\
\hline \multicolumn{7}{|c|}{ Age at diagnosis of $B C$ in FDR } \\
\hline$\leq 50$ years old & 967 & 1.89 & $1.78-2.02$ & 11 & 1.72 & $0.95-3.10$ \\
\hline$>50$ years old & 4378 & 1.63 & $1.58-1.68$ & 287 & 1.67 & $1.49-1.88$ \\
\hline \multicolumn{7}{|l|}{ Type of the affected FDR } \\
\hline Only mother & 3716 & 1.70 & $1.64-1.76$ & 224 & 1.69 & $1.48-1.93$ \\
\hline Only sister & 1597 & 1.61 & $1.53-1.69$ & 68 & 1.59 & $1.25-2.83$ \\
\hline Only brother or father & 32 & 1.77 & $1.25-2.51$ & 6 & 2.19 & $0.98-4.87$ \\
\hline
\end{tabular}

${ }^{\mathrm{a}} \mathrm{N}$, number of $\mathrm{BC}$ cases diagnosed during the follow-up in women

${ }^{b}$ RR was estimated from Poisson regression using individuals without cancer family history as the reference. The covariates adjusted in the model included age groups (5 years), periods (5 years), parity (number of live birth: 0, 1, 2, 3, over 3), socioeconomic status (blue-collar worker, white-collar worker, farmer, private business, professional, or other/unspecified) and place of residence (big cities, northern Sweden, southern Sweden and unspecific). Significant RRs are in bold $B C$ breast cancer, $B C a-1$ breast cancer as a first primary malignancy, $B C a-2$ breast cancer as a second primary malignancy, FDR first-degree relative, $R R$ relative risk, 95\% Cl 95\% confidence interval

We present the results without removing women with more than one FDR affected by $\mathrm{BCa}-1$ or $\mathrm{BCa}-2$ and women with FDRs affected by cancer after $\mathrm{BCa}-1$ and BCa-2 in Supplementary Table 1. The BC risks for family history of $\mathrm{BCa}-1(1.74,1.69$ to 1.78$)$ and $\mathrm{BCa}-2$ (1.77, 1.60 to 1.96$)$ both increased but were still similar. In the analysis considering the number of the affected relatives, high risk was associated with more than one FDR diagnosed with $\mathrm{BCa}-2$ (4.33, 1.94 to 9.63$)$, but the case number was small $(N=2)$.

\section{Discussion}

With the increasing number of the $\mathrm{BCa}-2$, it is of great importance to investigate if familial risk differs between a family history of BCa-1 and BCa-2. Most of the studies involved with a family history of multiple primary cancers were set up in families with hereditary cancer syndrome [15]. No study has systematically investigated the $\mathrm{BC}$ risk when FDRs have $\mathrm{BCa}-2$ following a non-breast cancer diagnosis. The principal finding of this nationwide population-based cohort study was that a diagnosis of either $\mathrm{BCa}-1$ or $\mathrm{BCa}-2$ is associated with a similar $\mathrm{BC}$ risk for their family members,

We excluded women who had multiple FDRs affected by $\mathrm{BCa}-2$ and women who had FDRs affected by $\mathrm{BCa}-2$ then later developed with third, fourth or even fifth primary cancers, which could be the reason that we observed slightly lower familial risk (1.68). After removing those restrictions, the familial risk was comparable to those reported from other studies [2-4]. The risk pattern for proband type did not differ in the family history of $\mathrm{BCa}-1$ and $\mathrm{BCa}-2$. Consistent with other studies, the familial risk was higher when the relatives diagnosed with $\mathrm{BC}$ at a younger age. It has been reported that early-onset cancers are more likely to have a hereditary background than late-onset ones [16]. In a recent study, negative association was found between age of onset of $\mathrm{BC}$ and the fraction of $\mathrm{BC}$-associated germline mutation [17]. Interestingly, we did not observe an apparent
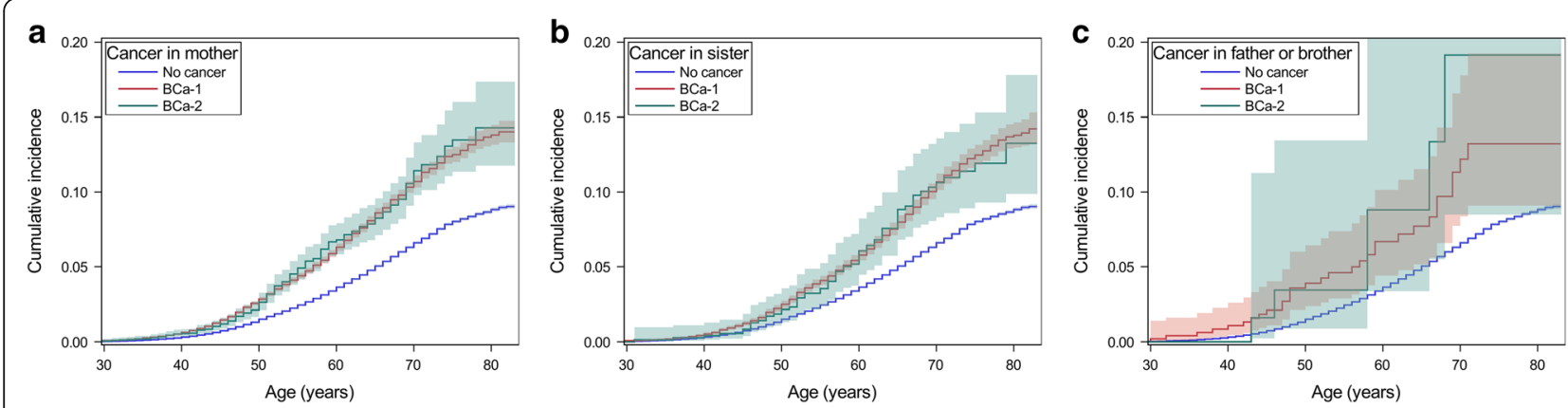

Fig. 2 Cumulative incidence of breast cancer from birth to a specific age in women who had mother (a), sister (b) and father or brother (c) affected by BCa-1, BCa-2 or no cancer. BCa-1, breast cancer as a first primary malignancy, BCa-2, breast cancer as a second primary malignancy. The shading band is the $95 \% \mathrm{Cl}$ confidence interval of the cumulative incidence 


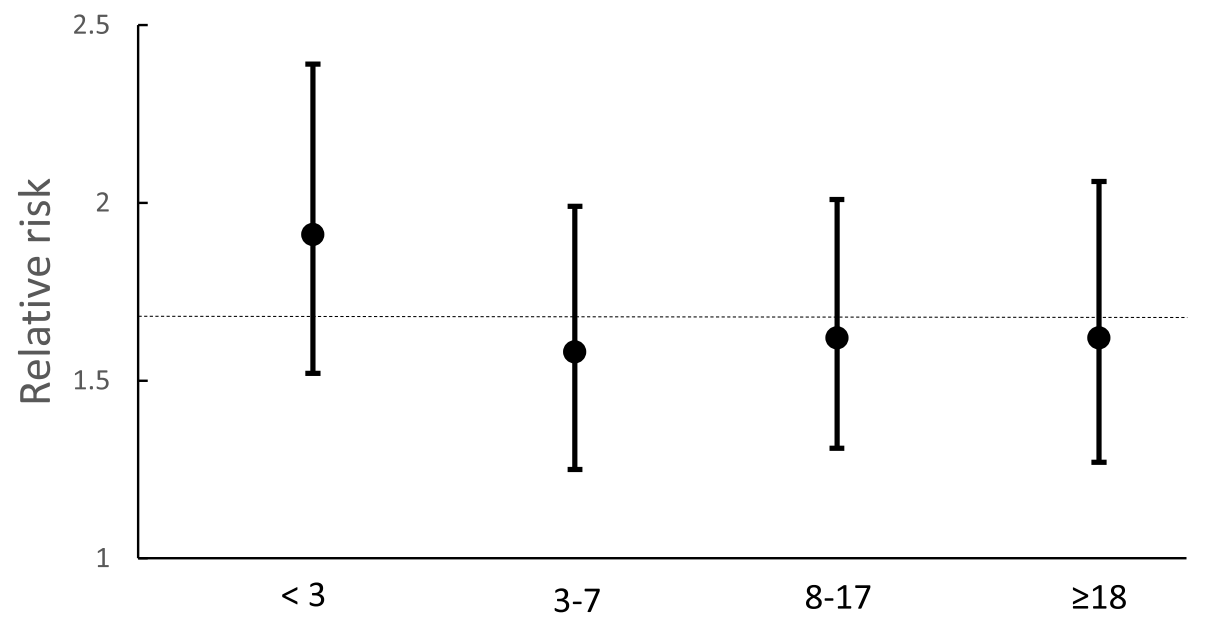

Years from first primary cancer to second primary breast cancer in relatives

Fig. 3 Breast cancer risk in women stratified by the time (in years) between first primary cancer and BCa- 2 in FDR. The dashed line is the overall risk of $\mathrm{BC}$ when one FDR was affected by $\mathrm{BCa}-2$. BCa-2, breast cancer as a second primary malignancy, FDR, first-degree relative

difference in risk between familial early- and lateonset $\mathrm{BCa}-2$. We speculate that this was due to the late-onset for most of the BCa-2 compared to BCa-1 and the current sample size was not able to provide enough power to distinguish the familial risk associated with the early- and late-onset BCa-2 in FDRs.

The development of the second primary cancers is linked to various factors which is partially indicated by the interval between first and second primary cancer diagnoses. The intensified medical surveillance increases the chance of second primary cancers diagnosed right after the first primary and those cancers are unlikely to be caused by the treatment from the first primary. Instead, treatment-related second primary cancers develop after several years from the first primary cancer diagnosis. In the analysis stratified by the time between the first primary cancer and $\mathrm{BCa}-2$ in relatives, despite fluctuation, the familial risks were largely consistent, implying the influences of medical surveillance and cancer treatments on familial risk of $\mathrm{BC}$ is limited.

The finding of the varied risk for a family history of BCa-2 after some specific cancers, indicates that the site of cancer before $\mathrm{BCa}-2$ gives a better prediction of $\mathrm{BC}$ risk. For endometrial and ovarian cancers, the increased risk can be explained by shared reproductive factors, the germline mutation manifested in hereditary breast and ovarian cancer syndrome or the interaction between them. The elevated risk with a FDR affected by first primary stomach cancer may be related to a type of hereditary diffuse gastric cancer associated with germline mutation of CHD1 [18]. For meningiomas, hormone level may have played role in the elevated $\mathrm{BC}$ risk in daughters [19]. As for endocrine tumors, the increased risk of $\mathrm{BC}$ may be associated with multiple endocrine neoplasia type 1 syndromes [20]. For smoking-related cancers as the first primary, with the exception of stomach cancer, a relatively lower risk of $\mathrm{BC}$ was found in $\mathrm{FDR}$ with $\mathrm{BCa}-2$ compared to that with $\mathrm{BCa}-1$. The further development of $\mathrm{BCa}-2$ in lung cancer patients could be due to radiotherapy that could be hardly shared by the family members. No study has reported radiotherapy-induced BC in lung cancer, possibly due to the poor survival of lung cancer, but a dose-response relationship for $\mathrm{BC}$ risk has been demonstrated in numerous medical radiation studies and researches on other malignancies such as Hodgkin lymphoma [21]. However, lung cancer only accounted for one-tenth of the smoking-related cancers, so other factors may also have contributed to the relatively lower risk. Smoking is also a risk factor for BC despite small effect size [22]. BC may have developed after smoking-related cancer due to smoking instead of strong hereditary factors. This is also supported by the late onset of BC (median age 60, IQR, 51-67) in daughters of relatives with first primary smoking-related cancers compared to the overall age of onset of the $298 \mathrm{BC}$ patients $(54,48-62)$.

\section{Clinical implication}

Family history has been an important determinant for the assessment of BC risk in commonly used models including NCI-Gail, BCSC, IBIS and BOADICEA [23, 24]. The dimension of the family history contains the degree and number of affected family members, diagnostic age of BC, bilateral or ipsilateral $\mathrm{BC}$ in relatives. None of them considered the order of the primary $\mathrm{BC}$ (either $\mathrm{BCa}-1$ or $\mathrm{BCa}-$ 2 here) diagnosed in FDRs. The comparable $\mathrm{BC}$ risk for family history of $\mathrm{BCa}-1$ and $\mathrm{BCa}-2$ in the current study suggests that a diagnosis of $\mathrm{BCa}-2$ in FDR can be treated as the same as $\mathrm{BCa}-1$ regarding $\mathrm{BC}$ risk prediction. 
Table 2 Breast cancer risk in women stratified by site of first primary cancer diagnosed before BCa-2 in their FDRs

\begin{tabular}{|c|c|c|c|c|}
\hline \multirow{2}{*}{$\begin{array}{l}\text { Site of first primary cancer before BCa-2 in FDR } \\
\text { UAT }{ }^{c}\end{array}$} & \multirow{2}{*}{$\begin{array}{l}N^{a} \\
5\end{array}$} & \multirow{2}{*}{$\begin{array}{l}\mathrm{RR}^{\mathrm{b}} \\
1.21\end{array}$} & \multicolumn{2}{|c|}{$95 \% \mathrm{Cl}$} \\
\hline & & & 0.50 & 2.90 \\
\hline Stomach ${ }^{c}$ & 6 & 3.92 & 1.76 & 8.72 \\
\hline Small intestine & 2 & 1.61 & 0.40 & 6.42 \\
\hline CRC & 44 & 1.60 & 1.19 & 2.15 \\
\hline Liver & 3 & 2.10 & 0.68 & 6.52 \\
\hline Lung $^{c}$ & 5 & 1.00 & 0.42 & 2.40 \\
\hline Cervix $^{c}$ & 16 & 1.46 & 0.89 & 2.38 \\
\hline Endometrium & 60 & 2.07 & 1.60 & 2.67 \\
\hline Ovary & 24 & 2.82 & 1.89 & 4.21 \\
\hline Female genital & 2 & 0.79 & 0.20 & 3.17 \\
\hline Prostate & 3 & 2.58 & 0.83 & 7.99 \\
\hline Kidney ${ }^{c}$ & 10 & 1.44 & 0.77 & 2.68 \\
\hline Bladder $^{c}$ & 8 & 1.00 & 0.50 & 2.00 \\
\hline Melanoma & 21 & 1.33 & 0.87 & 2.04 \\
\hline Skin & 11 & 1.11 & 0.61 & 2.01 \\
\hline Nervous system & 18 & 1.94 & 1.22 & 3.07 \\
\hline Thyroid & 10 & 1.54 & 0.83 & 2.86 \\
\hline Endocrine gland & 20 & 2.05 & 1.32 & 3.18 \\
\hline Bone & 1 & 0.80 & 0.11 & 5.69 \\
\hline Connective tissue & 4 & 1.89 & 0.71 & 5.05 \\
\hline $\mathrm{NHL}^{d}$ & 12 & 2.84 & 1.61 & 5.00 \\
\hline Hodgkin lymphoma ${ }^{d}$ & 3 & 2.06 & 0.67 & 6.40 \\
\hline Myeloma $^{d}$ & 1 & 1.59 & 0.22 & 11.29 \\
\hline Leukemia $^{d}$ & 4 & 0.85 & 0.32 & 2.26 \\
\hline CUP & 5 & 2.24 & 0.93 & 5.38 \\
\hline Smoking related cancers & 50 & 1.34 & 1.02 & 1.77 \\
\hline Hematological cancers & 20 & 1.82 & 1.17 & 2.81 \\
\hline Any cancer other than BC & 298 & 1.68 & 1.49 & 1.88 \\
\hline
\end{tabular}

${ }^{\mathrm{a}} \mathrm{N}$, number of $\mathrm{BC}$ cases diagnosed during the follow-up in women

${ }^{\mathrm{b}} \mathrm{RR}$ was estimated from Poisson regression using individuals without cancer family history as the reference. The covariates adjusted in the model included age groups (5 years), periods (5 years), parity (number of live birth: $0,1,2,3$, over 3), socioeconomic status (blue-collar worker, white-collar worker, farmer, private business, professional, or other/unspecified) and place of residence (big cities, northern Sweden, southern Sweden and unspecific). Significant RRs are in bold 'Cancers that were included as smoking-related cancers

${ }^{d}$ Cancers that were included as hematological cancers

$B C$ breast cancer, $B C a-2$ breast cancer as a second primary malignancy, FDR first-degree relative, UAT upper aerodigestive tract, $C R C$ colorectal cancer, NHL nonHodgkin lymphoma, CUP cancer of unknown primary, $R R$ relative risk, $95 \% \mathrm{Cl} 95 \%$ confidence interval

However, the varied familial risk according to the cancer site before $\mathrm{BCa}-2$ implies the necessity to include the first primary cancer into the consideration for family history of $\mathrm{BCa}-2$. For example, $\mathrm{BC}$ risk is high for women with FDRs affected by a BCa-2 after first primary stomach, endometrial and ovarian cancers and non-Hodgkin lymphoma. Although, due to the relatively small sample size, further investigation is warranted.

\section{Strengths and limitations of the study}

By using the Swedish national registries, we were able to obtain accurate family relationships and order of multiple primary cancers without information bias. We implemented very strict analyses to control the possible influences (such as the number of relatives with cancers) on the risk estimation. Analyses without the restrictions were also performed to generalize the results. We conducted multiple stratification analyses to characterize $\mathrm{BC}$ risk with the family history of $\mathrm{BCa}-2$. The family history can be defined in dynamic and static scale depending on if the presence of the disease in FDRs is considered as time-varying and time-fixed. The two methods generate a similar estimation of relative risk $[25,26]$, so the results from the current study using the static method 
would not deviate much from that using the dynamic method. Some limitations need to be addressed. The case number was not adequate to estimate risk for family history from male relatives, and the same issue persisted with some specific first primary cancers. In addition to parents and siblings, offspring is usually defined as an FDR, but we did not include it in the analysis, as it is very rare for parents to have $\mathrm{BC}$ after $\mathrm{BCa}-2$ diagnosis in offspring since the median diagnostic age of $\mathrm{BCa}-2$ is 68 . Our study did not adjust for the number of sisters although sibling risk of $\mathrm{BC}$ has been reported to increase with the increasing number of sisters [27]. Data on some $\mathrm{BC}$ risk factors like smoking, physical activity and diet were unavailable along with information on treatment for the first primary cancer and individual germline mutation, making some of the discussion on the association with other first primary cancers speculative at best. The hormonal status of $\mathrm{BC}$ was not known, which could have given more precise risk estimation. We did not find any explanation for high risk associated with diagnosis of non-Hodgkin lymphoma as first primary cancer in FDR and more studies are needed to investigate the association.

\section{Conclusions}

As far as we are aware, we for the first time, provided information on $\mathrm{BC}$ risk assessment for women with family history of $\mathrm{BCa}-2$. The similar $\mathrm{BC}$ risk indicates that women with FDR affected by $\mathrm{BCa}-2$ can be managed similarly as those with FDR affected by $\mathrm{BCa}-1$, regarding $\mathrm{BC}$ prevention and screening. In addition, for those with family history of $\mathrm{BCa}-2$, the familial risk varies most according to the site of first primary cancer in FDR, which should be considered in the clinical practice.

\section{Supplementary Information}

The online version contains supplementary material available at https://doi. org/10.1186/s12885-021-08925-y.

Additional file 1. Supplementary Figure 1. The flowchart of the population selection. Supplementary Table 1. Breast cancer risk in women when FDRs were diagnosed with BCa-1 or BCa-2.*

\section{Acknowledgements}

We thank Patrick Reilly for his proofreading.

\section{Authors' contributions}

Design: JJ, GZ. Acquisition of data: JS, KS. Statistical analysis and interpretation: GZ, JJ, JS, KS. Manuscript writing: GZ and all other authors. Approval of the final text: All authors. All authors read and approved the final manuscript.

\section{Funding}

This work was supported by the Swedish Research Council [2016-02373 to J.J., 2018-02400 to K.S., 2020-01175 to J.S.], Cancerfonden [2017 CAN2017/ 340 to J.J.], Crafoordska Stiftelsen [to J.J.], MAS Cancer [to J.J.], ALF funding from Region Skåne [to J.J. and K.S.]. The funding body was not involved in the design of the study and collection, analysis, and interpretation of data and in writing the manuscript. Open Access funding provided by Lund University.

\section{Availability of data and materials}

The data that support the findings of this study are available from Lund University but restrictions apply to the availability of these data, which were used under license for the current study and so are not publicly available. Any request regarding the data from this study should go to the last author (J.J.)

\section{Declarations}

Ethics approval and consent to participate

We secured ethical approval and waiver of informed consent (February 6, 2013) for this study from the Regional Ethical Review Board of Lund University (Dnr 2012/795). Patient consent was not required as the study used only deidentified registry based secondary data. All methods were performed in accordance with the relevant guidelines and regulations.

\section{Consent for publication}

Not applicable.

\section{Competing interests}

The authors declare no competing interests.

\section{Author details}

${ }^{1}$ Center for Primary Health Care Research, Lund University/Region Skåne, Jan Waldenströms gata 35, 20502 Malmö, Sweden. ²Department of Family Medicine and Community Health, Department of Population Health Science and Policy, Icahn School of Medicine at Mount Sinai, New York, USA. ${ }^{3}$ Center for Community-based Healthcare Research and Education (CoHRE), Department of Functional Pathology, School of Medicine, Shimane University, Izumo, Japan.

Received: 21 May 2021 Accepted: 14 October 2021

Published online: 12 November 2021

\section{References}

1. Bray F, Ferlay J, Soerjomataram I, Siegel RL, Torre LA, Jemal A. Global cancer statistics 2018: GLOBOCAN estimates of incidence and mortality worldwide for 36 cancers in 185 countries. CA Cancer J Clin. 2018;68(6):394-424. https://doi.org/10.3322/caac.21492.

2. Frank C, Fallah M, Ji J, Sundquist J, Hemminki K. The population impact of familial cancer, a major cause of cancer. Int J Cancer. 2014;134(8):1899-906. https://doi.org/10.1002/ijc.28510.

3. Frank C, Fallah M, Sundquist J, Hemminki A, Hemminki K. Population landscape of familial cancer. Sci Rep. 2015;5(1):1-8. https://doi.org/10.1038/ srep12891.

4. Goldgar DE, Easton DF, Cannon-Albright LA, Skolnick MH. Systematic population-based assessment of cancer risk in first-degree relatives of cancer probands. JNCl: J Natl Cancer Inst. 1994;86(21):1600-8. https://doi. org/10.1093/jnci/86.21.1600.

5. Narayan AK, Lee Cl, Lehman CD. Screening for breast cancer. Med Clin N Am. 2020;104(6):1007-21. https://doi.org/10.1016/j.mcna.2020.08.003.

6. Mukama T, Kharazmi E, Xu X, Sundquist K, Sundquist J, Brenner H, et al. Riskadapted starting age of screening for relatives of patients with breast cancer. JAMA Oncol. 2020;6(1):68-74. https://doi.org/10.1001/jamaoncol.201 9.3876 .

7. Feller A, Matthes KL, Bordoni A, Bouchardy C, Bulliard J-L, Herrmann C, et al. The relative risk of second primary cancers in Switzerland: a populationbased retrospective cohort study. BMC Cancer. 2020;20(1):51. https://doi. org/10.1186/s12885-019-6452-0.

8. Ji J, Sundquist K, Sundquist J, Hemminki K. Comparability of cancer identification among death registry, cancer registry and hospital discharge registry. Int J Cancer. 2012;131(9):2085-93. https://doi.org/10.1002/ijc.27462

9. Hemminki $\mathrm{K}, \mathrm{Ji}$ J, Forsti A. Risks for familial and contralateral breast cancer interact multiplicatively and cause a high risk. Cancer Res. 2007;67(3):868-70 https://doi.org/10.1158/0008-5472.CAN-06-3854.

10. Frödin J-E, Ericsson J, Barlow L. Multiple primary malignant tumors in a national cancer registry: Reliability of reporting. Acta Oncol. 1997;36(5):4659. https://doi.org/10.3109/02841869709001300. 
11. Lorenzo Bermejo J, Hemminki K. A population-based assessment of the clustering of breast cancer in families eligible for testing of BRCA1 and BRCA2 mutations. Ann Oncol. 2005;16(2):322-9. https://doi.org/10.1093/a nnonc/mdi041.

12. Zheng G, Yu H, Hemminki A, Försti A, Sundquist K, Hemminki K. Familial associations of female breast cancer with other cancers. Int J Cancer. 2017; 141(11):2253-9. https://doi.org/10.1002/ijc.30927.

13. Al-Ajmi K, Lophatananon A, Ollier W, Muir KR. Risk of breast cancer in the UK biobank female cohort and its relationship to anthropometric and reproductive factors. PLoS One. 2018;13(7):e0201097. https://doi.org/10.13 71/journal.pone.0201097.

14. US Department of Health and Human Services. The health consequences of smoking: a report of the Surgeon General. 2004.

15. Cybulski C, Nazarali S, Narod SA. Multiple primary cancers as a guide to heritability. Int J Cancer. 2014;135(8):1756-63. https://doi.org/10.1002/ijc.2 8988.

16. Brandt A, Bermejo JL, Sundquist J, Hemminki K. Age of onset in familial cancer. Ann Oncol. 2008;19(12):2084-8. https://doi.org/10.1093/annonc/ mdn527.

17. Maxwell KN, Wenz BM, Kulkarni A, Wubbenhorst B, D'Andrea K, Weathers B, et al. Mutation rates in cancer susceptibility genes in patients with breast Cancer with multiple primary cancers. JCO Precis Oncol. 2020;4(4):916-25. https://doi.org/10.1200/PO.19.00301.

18. Pharoah PD, Guilford P, Caldas C, International Gastric Cancer Linkage Consortium. Incidence of gastric cancer and breast cancer in $\mathrm{CDH1}$ (E-cadherin) mutation carriers from hereditary diffuse gastric cancer families. Gastroenterology. 2001;121(6):134853. https:/doi.org/10.1053/gast.2001.29611.

19. Qi Z-Y, Shao C, Huang Y-L, Hui G-Z, Zhou Y-X, Wang Z. Reproductive and exogenous hormone factors in relation to risk of meningioma in women: a meta-analysis. PLoS One. 2013;8(12):e83261. https://doi.org/10.1371/journal. pone.0083261.

20. Jeong YJ, Oh HK, Bong JG. Multiple endocrine neoplasia type 1 associated with breast cancer: a case report and review of the literature. Oncol Lett. 2014;8(1):230-4. https://doi.org/10.3892/ol.2014.2144.

21. Gilbert ES. Ionising radiation and cancer risks: what have we learned from epidemiology. Int J Radiat Biol. 2009;85(6):467-82. https://doi.org/10.1080/ 09553000902883836.

22. Gram IT, Park S-Y, Maskarinec G, Wilkens LR, Haiman CA, Le Marchand L. Smoking and breast cancer risk by race/ethnicity and oestrogen and progesterone receptor status: the multiethnic cohort (MEC) study. Int J Epidemiol. 2019;48(2):501-11. https://doi.org/10.1093/ije/dyy290.

23. McClintock AH, Golob AL, Laya MB. Breast Cancer Risk Assessment: A StepWise Approach for Primary Care Providers on the Front Lines of Shared Decision Making. Mayo Clin Proc. 2020;95(6):1268-75.

24. Lee A, Mavaddat N, Wilcox AN, Cunningham AP, Carver T, Hartley S, et al. BOADICEA: a comprehensive breast cancer risk prediction model incorporating genetic and nongenetic risk factors. Genet Med. 2019;21(8): 1708-18. https://doi.org/10.1038/s41436-018-0406-9.

25. Mukama T, Kharazmi E, Sundquist K, Sundquist J, Brenner H, Fallah M. Familial risk of breast cancer by dynamic, accumulative, and static definitions of family history. Cancer. 2020;126(12):2837-48. https://doi.org/ $0.1002 /$ cncr.32815.

26. Brandt A, Bermejo JL, Sundquist J, Hemminki K. Familial risks of breast and prostate cancers: does the definition of the at risk period matter? Eur J Cancer. 2010;46(4):752-7. https://doi.org/10.1016/j.jca.2009.11.016.

27. Frank C. Population landscape of familial Cancer. Doctoral dissertation. Heidelberg University; 2016.

\section{Publisher's Note}

Springer Nature remains neutral with regard to jurisdictional claims in published maps and institutional affiliations.

Ready to submit your research? Choose BMC and benefit from:

- fast, convenient online submission

- thorough peer review by experienced researchers in your field

- rapid publication on acceptance

- support for research data, including large and complex data types

- gold Open Access which fosters wider collaboration and increased citations

- maximum visibility for your research: over $100 \mathrm{M}$ website views per year

At BMC, research is always in progress.

Learn more biomedcentral.com/submissions 